\title{
Very atypical agreement indeed
}

MICHAEL CYSOUW

\section{What is agreement, anyway?}

In their thorough reappraisal of the lengthy scholarly debate about pointing and directional verbs in sign languages, Lilo-Martin \& Meier (LM\&M, this volume) argue that (i) both pointing and directionality in sign language are comparable to person marking in spoken languages, and (ii) directionality in sign language is comparable to agreement in spoken languages. The first proposition (i) is well-argued for, but the second (ii) is not. The authors seem to assume that by arguing for (i) they implicitly have argued for (ii), but this indicates a misconception of the meaning of the term agreement.

Without taking any issue with Lilo-Martin \& Meier's arguments themselves (which in the case of person marking seem perfectly legitimate to me), their arguments do not substantiate the claim that directionality is similar to agreement in spoken language. At most, directionality seems to be an extremely non-canonical form of agreement, which, as the authors write themselves "may $[\ldots]$ be an indication that an analysis using another approach would be more successful" (LM\&M §6.0). The problem seems to be that the authors equate the term 'agreement' with 'inflectional person marking'. Unfortunately, this interpretation is widespread in current linguistic theory, but it has little theoretical or practical validity.

In current linguistic practice two rather different notions of agreement are attested. The first notion, which I will designate as agreement/concord, defines agreement as some kind of systematic covariance of linguistic expressions, like in Italian singular il nuovo cuadro ('the new picture') vs. plural $i$ nuovi cuadri ('the new pictures', Corbett 2006: 9). The second usage, which I will call agreement/inflection, reduces the notion of agreement to subject-verb covariance only. And even more extremely, in this tradition often agreement 
simply designates any verb inflection with reference to the subject (e.g. as in the various articles in Boeckx 2006). Although Lilo-Martin \& Meier explicitly refer to Corbett (2006) as their source for the notion agreement, in practice they never use his definitions and criteria to evaluate the sign language phenomena. They simply interpret the similarity between directionality in sign language and person inflection in spoken language as sufficient evidence to call them both agreement. This only makes sense when agreement is interpreted as agreement/inflection, and not as Corbett's agreement/concord.

In this commentary, I will first present a concise history of the term agreement to clarify the origin of the contemporary terminological confusion. Following that, I will sketch the kind of argumentation needed to show that directionality is agreement/concord, only to conclude that this does not seem to be the most promising approach. Directionality can still be conceived as an slightly special example of agreement/inflection, but that only implies that directionality is a kind of inflectional person marking. If that is the desired conclusion, then I would propose to simply use the designation inflectional person marking instead of the confusing term agreement.

\section{A concise history of the term agreement}

The basic insight behind the notion 'agreement' is that there are various phenomena in human language that cannot be left unexpressed. Or, in different terms, various parts of human language are predictable to a certain extent, up the point of being completely redundant. For example, every reader of this sentence will immediately know what the last word of this sentence should $[\ldots]$. The investigation of such restrictions is the main objective of modern structuralistic linguistics, but the basic insight of the importance of such restrictions dates back at least to the Modists of the 12th Century. Scholarly discussion in that time developed many different analyses of purely grammatical restrictions of possible language structures, separating them from semantics. The central new concept introduced by the Modists was regere, of which the modern concept government is a direct descendant (Kneepkens 1978). Two further important terms in the current context are concordia and congruitas, apparently used as synonyms (Law 2003: 166). Although these terms are strikingly similar to the English term concord and the German term Kongruenz, it turns out that the link is not a direct one. The terms congruitas/concordia refer 
to a notion quite similar to the Chomskyan notion of grammaticality (Covington 1979: 479-480) in the sense that a sentence like "colourless ideas sleep furiously" is nonsensical, but grammatical. Congruitas/concordia is attained when all structural obligations are met by a sentence. One of these obligations is proper subject-verb agreement, which was referred to as similitudo by Thomas von Erfurt (Bursill-Hall 1972: 104; Covington 1979: 481).

Yet, the term similitudo vanished with the passing of time. In contrast, the term concord reappears in English grammatical descriptions as early as 1513 in William Lily's $A$ short introduction of grammar with a meaning similar to similitudo. Lily writes the following:

"Concords of Latin speech: for the due joyning of words in construction, it is to be understood, that in Latin Speech there be three Concords: The first, between the Nominative case and the Verb: The second between the Substantive and the Adjective: The third between the Antecedent and the Relative." (Lily 1503: D4r)

This notion of concord as covariation between words, which can be attested in various parts of the system of a language (e.g. between subject and verb, between noun and adjective, or in other constructions) will remain widespread as a common concept of linguistics for the centuries to come.

In modern German linguistics, the translation of the term concord is Kongruenz. Although the similarity to the Medieval term congruitas is striking, it appears that the term Kongruenz was introduced in the early 19th Century by Karl Ferdinand Becker in his Deutsche Sprachlehre of 1829, possibly in parallel to the widespread mathematical usage of the term:

"Ein Thätigkeitsbegriff z.B. blühen, groß wird auf den Begriff eines Seins, z.B. Baum, Hund dergestalt bezogen, dass beide Begriffe zu einer Einheit des Gedankens, z.B. "der Baum blühet," "der Hund ist groß," oder zu einer Einheit des Begriffes z.B. "der blühende Baum," "der große Hund" verbunden werden. Dieses Verhältniß der Einheit - die Kongruenz - von Thätigkeit und Sein wird durch die Kongruenz der Form ausgedrückt, welche sich in der Flexion des bezogenen Wortes blüh-et, blühend-e, groß-e darstellt." (Becker 1829: 14)

Now, the crucial figure that brings all these developments together was Leonard Bloomfield. He appears to have been the first to use the noun agreement as a technical linguistic term in his widely influential book Language: "in a rough way, without real boundaries, we can distinguish three general types of agreement" (Bloomfield 1933: 191-193). These three types of agreement 
are called concord/congruence, government, and cross-reference. Interestingly, Bloomfield discusses exactly these terms already in his 1914 book $A n$ introduction to the study of language, though without using the overarching term agreement (Bloomfield 1914: 178-180), so the coinage of the term agreement falls somewhere in between these two publications. There is of course a long tradition to use phrases like 'agree with' or 'in agreement with' in the linguistic literature, but these phrases always appear to be used in the general meaning of the words without any specific linguistic interpretation. The usage of the term agreement as a technical linguistic term started with Bloomfield (1933).

There are various notable aspects in this coinage of the term agreement. First, Bloomfield appears to treat the terms concord and congruence as synonyms. This most likely is not because he knew about 12th Century linguistics, but because he was intimately acquainted with the German linguistic scene in which Kongruenz was used roughly synonymous with the English term concord. Second, and more importantly, Bloomfield introduced the new term as a cover term to express the intuition that there is a strong similarity between the concepts of government and concord (see Corbett 2006: 7-8 for a discussion). Both these concepts express some purely structural restrictions on linguistic expressions, which is exactly the intuition that lead to the extensive discussion in the 12th Century. Bloomfield possibly felt that there was a need for a new term to surpass the entrenched terms concord and government, and their respective analyses.

Bloomfield's attempt to introduce an overarching concept failed. In the wake of the large influence of Bloomfield on linguistics, the term agreement caught on in the linguistic literature, but it was not used in the sense as proposed by him. Ever since Bloomfield, the term agreement seems basically to have been interpreted as a replacement of concord (cf. Corbett 2006: 5-7 for some examples of the resulting terminological confusion). Still based in the old tradition, Hockett (1958: 214) uses the term concord, but he notes that it is "often called agreement". Representing the new terminology, Chomsky (1965) uses the term agreement to refer to erstwhile typical cases of concord, e.g. "the grammar must contain agreement rules that assign to the Article all of the feature specifications for [Gender], [Number], and [Case] of the Noun it modifies" (Chomsky 1965: 174-175). More recently, starting with Steele (1978) and Moravcsik (1978), and culminating in the thorough analysis of Corbett (2006), the original intuition behind Lily's term concord has completely been replaced 
with the new term agreement. I think this development is unfortunate, because there is nothing gained by using the term agreement instead of concord. However, such a development is neigh impossible to revert, so the best we can do is not to confuse the situation even more.

However, this is exactly what happened. Most confusingly, there is a parallel development in the usage of the term agreement with a rather different outcome. In the context of Government \& Binding (Chomsky 1981), the term agreement became restricted to person-number-gender inflection on verbs (abbreviated as AGR). i.e. only the first of the Lily 'concords'. As a further development, all person/number/gender inflection on the verb with reference to the subject is today often simply called agreement (cf. Boeckx 2006). In this conceptualization, the Bloomfieldian notions concord and cross-reference get blurred, resulting in a large confusion in the literature (see Corbett 2003; Corbett 2006: 99-112). This terminological development is likewise extremely unfortunate, but too entrenched to be changed easily.

In summary, there are two rather different meanings of the term agreement in modern linguistic theory. The first interpretation refers to some kind of structural covariance and will be called agreement/concord here. The second interpretation seems to treat all subject inflection on verbs as agreement and will be called agreement/inflection.

\section{Directionality in sign language is not agreement/concord}

Returning to sign language, Lilo-Martin \& Meier argue (I think convincingly) that directionality is a kind of person marking, and that directionality has characteristics of inflectional marking (e.g. lexical idiosyncrasies, LM\&M $\S 4.2$ ). This immediately allows the conclusion that directionality is a kind of agreement/inflection. But, as I have argued before, it might be better to use the more transparent name inflectional person marking instead of using the confusing term agreement for this aspect of sign language.

However, Lilo-Martin \& Meier also claim that "the properties discussed [...] show that agreement in signed languages is not canonical in Corbett's (2006) sense [i.e. non-canonical agreement/concord, MC]" (LM\&M §6.1). Corbett indeed presents an explicit discussion of how to establish the canonicity of person agreement (Corbett 2003; Corbett 2006: 99-112), but Lilo-Martin $\&$ Meier do not follow that proposal at all. They present a few arguments that 
Table 1. Arguments for directionality in sign language being canonical agreement. The characteristics of sign language are indicated with bold face, arguing that directionality is strongly noncanonical agreement. It might be better interpreted as cross-reference.

\begin{tabular}{|c|c|c|c|c|}
\hline & \multicolumn{2}{|l|}{ Canonical Agreement } & \multicolumn{2}{|c|}{ Non-canonical Agreement } \\
\hline A: Morphology & \multicolumn{2}{|l|}{ Inflectional } & & Free \\
\hline B: Syntax & \multicolumn{2}{|c|}{ Fixed position of full NPs } & \multicolumn{2}{|c|}{ Free ordering of full NPs } \\
\hline C: Case & \multicolumn{2}{|c|}{ Single role inflection } & \multicolumn{2}{|c|}{ Multiple roles inflection } \\
\hline D: Referentiality & \multicolumn{2}{|l|}{ Possibly indefinite } & \multicolumn{2}{|c|}{ Always referential } \\
\hline E: Content of Reference & \multicolumn{2}{|l|}{ Anything } & \multicolumn{2}{|r|}{ Only persons } \\
\hline F: Distribution of Information & Less distinctions & & $\begin{array}{l}\text { ber } \\
\text { tions }\end{array}$ & More distinctions \\
\hline G: Multirepresentation & $\begin{array}{l}\text { Obligatorily double } \\
\text { marking }\end{array}$ & $\begin{array}{r}\text { Null } \\
\text { p }\end{array}$ & ients & $\begin{array}{r}\text { Impossible double } \\
\text { marking }\end{array}$ \\
\hline
\end{tabular}

do not have any relation to the canonicity of agreement (e.g. the classification of agreeing and non-agreeing verbs, and the set of backwards verbs), and the remaining arguments actually argue against canonical agreement.

Table 1 presents the different kinds of arguments proposed by Corbett to determine the canonicity of person agreement. The characteristics of directionality in sign language are shown in boldface, making it immediately obvious that directionality is extremely non-canonical person agreement. I will briefly discuss these arguments in turn. Morphologically (A), directionality seems to be alike to inflectional marking ( $L M \& M \S 6.1$ ), which is actually the only clear argument in favor of an agreement analysis. As for the syntax (B), sentences with directional verbs seem to have a freer word order of the full NPs in the sentence (LM\&M §7.1), which argues for the functional primacy of the directionality, and thus for non-canonical agreement. As for case (C), directional verbs can make reference to more than one argument, which Corbett treats as a sign of non-canonicity. The fact that there are some verbs in sign language that only refer to the object (LM\&M §6.1) has no clear influence on the status of agreement. Referentially (D), canonical agreement can refer to anything, including indefinites. However, in sign language pointing and directionality seems to be used only for personal reference, so this is a further sign of noncanonical agreement. The final two arguments are non-committal as to the canonicity of person agreement in sign language. First, the distribution of information (F) is equal between pointing and directional verbs (i.e. the kind of person distinctions attested is the same). Regarding multirepresentation (G), this criterion classifies the fact how common it is for the covarying elements to be 
both overtly present, i.e. whether null arguments are allowed or not. LiloMartin \& Meier write about this that "languages with rich agreement tend to allow null arguments, so the existence of null arguments in ASL is consistent with the analysis of directionality as agreement" (\$7.2). This argument has it completely backwards. First, directionality is clearly not rich agreement in any possible interpretation of richness (it has only a first vs. non-first distinction). So, the existence of null arguments in ASL does not seem to be determined by the richness of the agreement. Further, the existence of null arguments actually argues against canonical agreement.

In summary, directionality in sign language does not very much looks like agreement/concord at all. The alternative analysis, which seems to be much more suitable, is that the person marking of directional verbs in sign language is a kind of inflectional person cross-reference. There is actual content that is expressed by this marking, it is not just structural redundancy.

\section{Correspondence address: Ludwig Maximilian University Munich} cysouw@1mu.de

\section{References}

Becker, Karl Ferdinand. 1829. Deutsche Sprachlehre. Zweiter Band: Deutsche Grammatik. Frankfurt am Main: Hermann'sche Buchhandlung. (Edition as available on http://books.google.com/ books?id=RhpAAAAAYAAJ).

Bloomfield, Leonard. 1914. An Introduction to the Study of Language. Benjamins: Amsterdam.

Bloomfield, Leonard. 1933. Language. Allen \& Unwin: London.

Boeckx, Cedric. 2006. Agreement systems. Amsterdam: Benjamins.

Bursill-Hall, G L. 1972. Grammatica speculativa. London: Longman Publishing Group.

Chomsky, Noam. 1965. Aspects of the Theory of Syntax. Boston, MA: The MIT press.

Chomsky, Noam. 1981. Lectures on Government and Binding: The Pisa Lectures. Foris: Dordrecht.

Corbett, Greville G. 2003. Agreement: the range of the phenomenon and the principles of the Surrey Database of Agreement. Transactions of the Philological Society 101(2). 155-202.

Corbett, Greville G. 2006. Agreement. Cambridge: Cambridge University Press.

Covington, Michael A. 1979. The syntactic theory of Thomas of Erfurt. Linguistics 17(5-6). 465496.

Kneepkens, C. H. 1978. Master Guio and his view on government: on the twelfth century linguistic thought. Vivarium XVI(2). 108-141.

Law, Vivien. 2003. The history of linguistics in Europe from Plato to 1600. Cambridge: Cambridge University Press.

Lilo-Martin, Diane \& Richard P. Meier. 2011. On the linguistics status of 'agreement' in sign language. Theoretical Linguistics. this volume. 


\section{Michael Cysouw}

Lily, William. 1513. A short introduction of grammar. Oxford: At the Theatre. (Edition from 1709, as available at http://books.google.com/books?id=tdoFAAAAQAAJ).

Moravcsik, Edith A. 1978. Agreement. In: Joseph H Greenberg (ed.), Universals of Human Language, Volume 4, 331-374. Stanford, CA: Stanford University Press.

Steele, Susan A. 1978. Word order variation: A typological study. In: Joseph H Greenberg (ed.), Universals of Human Language, Volume 4, 585-623. Stanford, CA: Stanford University Press. 